\title{
Degradation and Regeneration Analysis in mc-Si
}

\author{
Annika Zuschlag, Daniel Skorka, and Giso Hahn \\ University of Konstanz, Department of Physics, 78457 Konstanz, Germany
}

\begin{abstract}
The performance of mc-Si PERC solar cells can be significantly affected by LeTID. The underlying mechanism causing LeTID is still unknown. This work compares the degradation and regeneration behavior under illumination and elevated temperature of an industrial mc-Si PERC solar cell to differently processed minority charge carrier lifetime samples. A strong degradation and also regeneration can be observed on lifetime level. Degradation and regeneration are strongly influenced by the applied process steps, like gettering, temperature load and surface passivation method. Therefore, lifetime studies offer a valuable possibility to identify further parameters influencing LeTID.
\end{abstract}

Index Terms - degradation, LeTID, multicrystalline, regeneration, silicon.

\section{INTRODUCTION}

Strong degradation of multicrystalline (mc) Si material is an issue that might hinder the passivated emitter and rear cell (PERC) technology to be applied to mc-Si. This degradation effect is observed upon illumination at moderate temperatures (e.g., [1]-[3]) and is referred to as light and elevated temperature induced degradation (LeTID) [3]. LeTID can cause efficiency losses up to $10 \%$ relative [3] and could therefore be a showstopper for the use of $\mathrm{mc}-\mathrm{Si}$ for new high efficiency solar cell concepts. Interestingly, also a regeneration effect can be observed at the same conditions used for degradation in solar cells at even longer timescales, starting after several hundreds of hours at $75^{\circ} \mathrm{C}$. Both effects are under detailed investigation, but the underlying mechanism of both, degradation and regeneration, are still unknown and cannot be attributed to standard BO-related degradation or FeB pair dissociation alone (e.g., [1]).

The published results are up to now mainly gained on solar cell or module level. The degradation of lifetime samples has been demonstrated by [3], but no regeneration has been observed. In case of [4], lifetime samples were used to calculate so called effective defect lifetime maps by comparing the initial and degraded effective minority charge carrier lifetime $\left(\tau_{\text {eff }}\right)$ distribution. The influence of different temperatures during firing on the degradation and regeneration behavior of lifetime samples is discussed in [5].

In this work, minority charge carrier lifetime degradation and regeneration is demonstrated on differently processed mc$\mathrm{Si}$ wafers focusing on the impact of a gettering step and different surface passivation methods. Due to a more flexible design of experiment, lifetime studies can be helpful to identify further processing parameters influencing degradation and regeneration kinetics leading to a more detailed fundamental understanding of the underlying mechanism of LeTID.

\section{EXPERIMENTAL}

Several differently processed lifetime samples are investigated to evaluate the impact of processing steps on the degradation and regeneration behavior of these lifetime samples. Additionally, an industrial mc-Si PERC solar cell is studied to link and compare the results to previously published results on LeTID.

The mc-Si material (1.5 $\Omega \mathrm{cm}$ boron doped) for the lifetime samples and the industrial solar cell originate from the same mc-Si ingot and the same ingot height, leading to a comparable initial material quality. In case of the lifetime samples, sister wafers with comparable grain and defect structure were used to focus on the influence of solar cell processing steps and less on differences in the defect distribution of the samples.

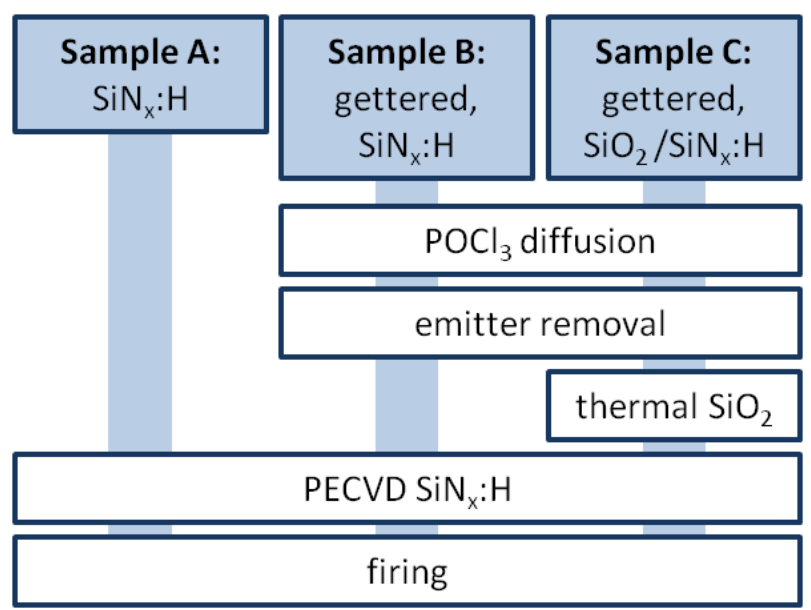

Fig. 1. Process sequence of the investigated lifetime samples.

Fig. 1 shows a scheme of the applied processing sequence. A chemical etch is applied to all samples to remove the saw damage. Two samples $(\mathrm{B}+\mathrm{C})$ were gettered by a $\mathrm{POCl}_{3}$ diffusion $(55 \Omega / \square)$, followed by an etching step to remove the emitter. In case of the ungettered (A) and one of the gettered samples (B), surface passivation is realized by a PECVD $\mathrm{SiN}_{\mathrm{x}}: \mathrm{H}$ layer, while the gettered sample $(\mathrm{C})$ is passivated by a stack of thermal $\mathrm{SiO}_{2}(6 \mathrm{~nm})$ and a PECVD $\mathrm{SiN}_{\mathrm{x}}: \mathrm{H}$ layer. All samples are fired in a belt furnace with a measured peak wafer temperature of $730^{\circ} \mathrm{C}$. 
The lifetime samples and the solar cell were stored on hotplates $\left(75^{\circ} \mathrm{C}\right)$ under illumination $(0.9 \pm 0.05$ suns for lifetime samples, $1 \pm 0.05$ sun for the solar cell). In case of the industrial solar cell, automated open circuit voltage $\left(\mathrm{V}_{\mathrm{OC}}\right)$ measurements are performed to characterize in situ the degradation and regeneration behavior at $75^{\circ} \mathrm{C}$. In case of lifetime samples, the fast and self-calibrated time resolved photoluminescence imaging (TR-PLI) method [6, 7] is used to gain spatially resolved $\tau_{\text {eff }}$ maps at different states of degradation. This series of lifetime maps of each $5 \times 5 \mathrm{~cm}^{2}$ mc-Si sample over degradation time is analyzed in detail by the following approach: An array of 2,500 areas, each $150 \times 150 \mu \mathrm{m}^{2}$ in size, is distributed over the $\tau_{\text {eff }}$ map. Average $\tau_{\text {eff }}$ values of these areas are extracted and plotted over degradation time. The values are coded by a rainbow color bar based on areas' $\tau_{\text {eff }}$ value at the beginning of the experiment. The single data points of each area are connected by lines as guides to the eye, which allows easily tracking of changes in $\tau_{\text {eff }}$ over degradation time for sample areas of different initial material quality. Therefore, the complete information of the spatially resolved TR-PLI over degradation time can be displayed.

\section{RESULTS AND CONCLUSIONS}

The in situ measured $\mathrm{V}_{\mathrm{OC}}$ data of the industrial mc-Si PERC solar cell (Fig. 2) confirm previously published results (e.g., [3]), and show a degradation of approx. $12 \%$ rel. after $200 \mathrm{~h}$ at $75^{\circ} \mathrm{C}$ and 1 sun illumination. Afterwards, a regeneration process is observed and the $\mathrm{V}_{\mathrm{OC}}$ data recovers almost completely.

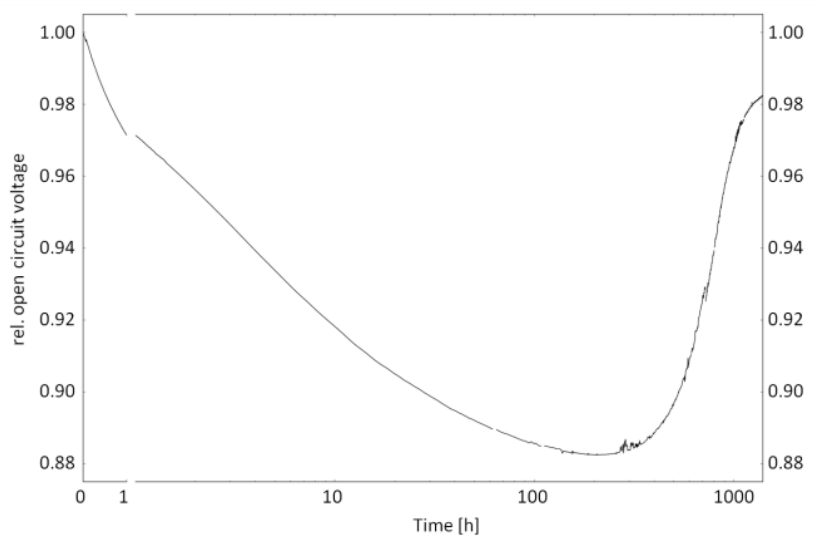

Fig. 2. Continuously measured $\mathrm{V}_{\mathrm{oc}}$ data of an industrial mc-Si PERC solar cell showing degradation and beginning regeneration behavior.

The behavior of $\tau_{\text {eff }}$ for three different lifetime sister samples is shown in Fig. 3. Each single line connects single data points (guide to the eye) and each represents a small area on the lifetime samples as described above. A fast degradation within the first minutes directly after firing is observed for all three differently processed lifetime samples and could be attributed to FeB- and/or BO-based degradation effects. After this fast degradation the behavior of the three samples differs in the strength of the degradation and the $\tau_{\text {eff }}$ distribution in dependence of the degradation state. A regeneration process is only observed for samples $\mathrm{A}$ and $\mathrm{C}$. The maximum degradation level for $\tau_{\text {eff }}$ in case of sample $A$ or $C$ is reached after approximately the same degradation time as for the solar cell applying the same degradation conditions. This leads to the assumption that the underlying degradation and regeneration mechanism can be investigated also on lifetime level and the gained results can be applied on solar cells, too.

The applied color code in Fig. 3 allows analyzing different sample areas with different initial $\tau_{\text {eff }}$ over degradation time. The relative $\tau_{\text {eff }}$ distribution of each single sample is nearly kept constant during the experiment, which means that sample areas with the highest initial $\tau_{\text {eff }}$ show also the highest $\tau_{\text {eff }}$ during the degradation process and also during regeneration in case of samples A and C.

The strongest degradation is observed on the ungettered sample A. The relative degradation in areas of higher initial lifetime is stronger than in areas of lower initial lifetime. At maximum degradation level, the initial $\tau_{\text {eff }}$ distribution (20$450 \mu \mathrm{s})$ is narrowed down to a very small $\tau_{\text {eff }}$ distribution (approx. 5-30 $\mu \mathrm{s}$ ). The strong degradation of the whole sample even in areas of high initial $\tau_{\text {eff, }}$ as shown also in the lifetime maps included in Fig. 3a, could be explained by a rather homogenous formation of recombination active defects over the whole sample area.

To check whether the observed effect is originating from mc-Si bulk degradation and not only from surface passivation issues, an additional sample is prepared exactly like sample A and degraded under the same conditions. The $\mathrm{SiN}_{\mathrm{x}}: \mathrm{H}$ surface passivation layer of the additional sample is etched back after approx. $300 \mathrm{~h}$ of degradation. After a chemical surface passivation (iodine ethanol, e.g., [8]) the sample is measured again by TR-PLI confirming the low $\tau_{\text {eff }}$ values and $\tau_{\text {eff }}$ distribution at this degradation state. Therefore, the observed strong degradation is mainly a bulk effect and cannot be attributed solely to changes in surface passivation quality of the $\mathrm{SiN}_{\mathrm{x}}: \mathrm{H}$ layer.

A regeneration process of sample $A$ is observed to set in after approximately $300 \mathrm{~h}$. The regeneration sets in first in areas of higher initial $\tau_{\text {eff }}$ (red lines). Regarding the narrow $\tau_{\text {eff }}$ distribution at maximum degradation level $(5-30 \mu \mathrm{s})$, the different starting points for observable regeneration in areas of different initial lifetime are remarkable. Nevertheless, the different lifetimes lead to different injection levels which might influence the observed regeneration kinetics. While there is no clear difference in the degradation time constants for areas of different initial material quality, the different starting points for regeneration reveal that the underlying mechanism for regeneration seems to be more complex. 

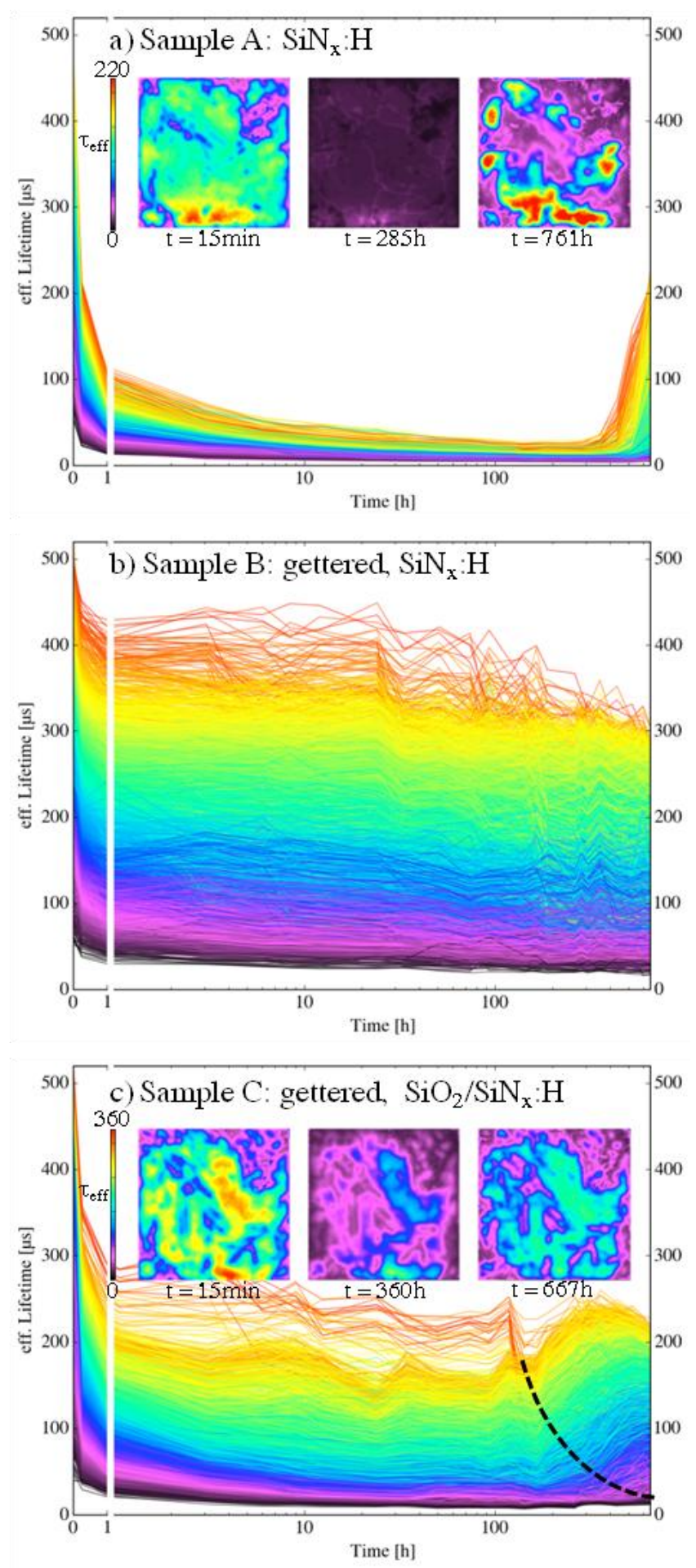

Fig. 3. Effective minority charge carrier lifetime of differently processed sister wafers A $\left(\mathrm{SiN}_{\mathrm{x}}: \mathrm{H}\right), \mathrm{B}$ (gettered, $\left.\mathrm{SiN}_{\mathrm{x}}: \mathrm{H}\right)$, and $\mathrm{C}$ (gettered, $\mathrm{SiO}_{2} / \mathrm{SiN}_{\mathrm{x}}: \mathrm{H}$ ) (first1 h: linear scale, afterwards: log-scale). Each line in the graph represents an area of $150 \times 150 \mu \mathrm{m}^{2}$ in the spatially resolved TR-PLI lifetime measurements and is color-coded according to its value at the beginning of degradation. Lines are guides to the eye only.
In contrast to sample A, the gettered sample B (Fig. 3b) is significantly less sensitive to LeTID and shows only a slight $\tau_{\text {eff }}$ reduction within the first minutes. The $\tau_{\text {eff }}$ range (approx. $20-500 \mu \mathrm{s})$ is only slightly narrowed down during the experiment. No clear maximum degradation level and no regeneration process are observed. Instead, the minority charge carrier lifetime seems to stay almost constant in the different sample areas.

Almost the same result is observed if only the temperature profile of a $\mathrm{POCl}_{3}$ diffusion is applied to a lifetime sample (not shown). This leads to the assumption, that the observed differences in behavior compared to sample A are mainly driven by the additional temperature load and not necessarily only by the $\mathrm{POCl}_{3}$ induced gettering effect.

The surface passivation of sample $\mathrm{C}$ is realized by firing a stack of thermal $\mathrm{SiO}_{2}$ and PECVD $\mathrm{SiN}_{\mathrm{x}}: \mathrm{H}$, leading to significant differences in degradation and regeneration behavior. Overall degradation and regeneration behavior is closer to the ungettered sample A than to sample B. As observed for sample A, sample $\mathrm{C}$ shows also a maximum degradation level and a narrowing of the $\tau_{\text {eff }}$ range, but not as significant as sample A. The regeneration process again starts earlier for sample areas with higher initial lifetimes as indicated by a black dashed line in Fig. 3c.

While the discussion of samples A and B has led to the assumption that concentration and distribution of $\tau_{\text {eff }}$ limiting bulk defects have an impact on the degradation and regeneration process, the comparison of the gettered samples B and C shows that also different surface passivation methods play an important role. Especially the thermal oxidation process can lead to an additional redistribution of impurities, which might (at least partly) explain the more significant degradation compared to sample B. First results on an additional lifetime sample $\mathrm{D}$, gettered and surface passivated by an $\mathrm{AlO}_{\mathrm{x}} / \mathrm{SiN}_{\mathrm{x}}: \mathrm{H}$ stack, show a stronger degradation than for sample $\mathrm{B}$ (gettered, $\mathrm{SiN}_{\mathrm{x}}: \mathrm{H}$ ) but weaker than in case of sample $\mathrm{C}$ (gettered, thermal $\mathrm{SiO}_{2} / \mathrm{SiN}_{\mathrm{x}}: \mathrm{H}$ ).

The applied data analysis of the $\tau_{\text {eff }}$ data over degradation time is even extended in [9]. This analysis leads to the result that in case of ungettered samples areas with higher initial $\tau_{\text {eff }}$ show a stronger degradation effect under degradation conditions than areas of lower initial $\tau_{\text {eff, }}$, while the opposite is observed for gettered samples.

The influence of different gettering steps is also discussed in [10] and [11], and a first rough model is introduced therein. Gettering seems to be very effective to suppress LeTID in areas of good material quality and low density of extended crystal defects. The gettering effectiveness is lower in areas of lower material quality and higher extended defect density, where, e.g., impurities in form of precipitates are harder to getter externally. 


\section{SUMMARY}

Spatially resolved $\tau_{\text {eff }}$ data from TR-PLI have demonstrated the influence of different solar cell processing steps on LeTID and regeneration behavior. An effective P-gettering step drastically reduces the strength of degradation, while following high temperature steps, like, e.g., the application of a thermal $\mathrm{SiO}_{2}$, partly reactivates LeTID. An explanation of these findings could be that previously applied gettering and temperature steps result in different contamination levels in the mc-Si bulk. This influences strongly the observed degradation and regeneration kinetics of the investigated lifetime samples. Each high temperature step after P-gettering leads to a redistribution of impurities.

\section{ACKNOWLEDGEMENT}

The authors would like to thank Lisa Mahlstädt, David Sperber, and Axel Herguth for help during sample preparation, sample characterization, and fruitful discussions. Part of this work was funded by the German Federal Ministry of Economics and Energy and by industrial partners within the research project "SolarLIFE" (0325763B) and within project no. 0325581 . The content of this work is the responsibility of the authors.

\section{REFERENCES}

[1] K. Ramspeck, S. Zimmermann, H. Nagel, A. Metz, Y. Gassenbauer, B. Birkmann, A. Seidl, "Light induced degradation of rear passivated mc-Si solar cells," Proc. $27^{\text {th }} E U$ PVSEC, Frankfurt/Main, Germany, 2012, pp.861-865.
[2] F. Fertig, K. Krauss, S. Rein, "Light-induced degradation of PECVD aluminium oxide passivated silicon solar cells," Phys. Status Solidi RRL 9(1),, pp. 41-46, 2014.

[3] F. Kersten, P. Engelhart, H.-C. Ploigt, A. Stekolnikov, T. Lindner, F. Stenzel, M. Bartzsch, A. Szpeth, K. Petter, J. Heitmann, J. Müller, "Degradation of multicrystalline silicon solar cells and modules after illumination at elevated temperature," Solar Energy Materials \& Solar Cells 142, pp. 83-86, 2015.

[4] K. Krauss, F. Fertig, D. Menzel, S. Rein, "Light-induced degradation of silicon solar cells with aluminium oxide passivated rear side," Energy Procedia 77, pp. 599-606, 2015.

[5] D. Bredemeier, D. Walter, S. Herlufsen, J. Schmidt, "Lifetime degradation and regeneration in multicrystalline silicon under illumination at elevated temperature," AIP Advances 6, p. 035119, 2016.

[6] D. Kiliani, G. Micard, B. Steuer, B. Raabe, A. Herguth, G. Hahn, "Minority charge carrier lifetime mapping of crystalline silicon wafers by time-resolved photoluminescence imaging," J. Appl. Phys. 110, p. 054508, 2011.

[7] D. Kiliani, A. Herguth, G. Micard, J. Ebser, G. Hahn, "Timeresolved photoluminescence imaging with electronic shuttering using an image intensifier unit," Solar Energy Materials \& Solar Cells 106, pp. 55-59, 2012.

[8] K. Pollock, J. Junge, G. Hahn, "Detailed investigation of surface passivation methods for lifetime measurements on silicon wafers," IEEE Journal of Photovoltaics 2(1), pp. 1-6, 2012.

[9] A. Zuschlag, D. Skorka, G. Hahn, "Degradation and regeneration analysis in mc-Si," Proc. $32^{\text {nd }}$ EU PVSEC, Munich, Germany, 2016, accepted

[10] A. Zuschlag, D. Skorka, G. Hahn, "Degradation and regeneration in mc-Si after different gettering steps," Progress in Photovoltaics: Research and Applications, 2016, submitted

[11] A. Zuschlag, D. Skorka, G. Hahn, "Degradation and regeneration in mc-Si after different gettering steps," Proc. $32^{\text {nd }}$ EU PVSEC, München, Germany, 2016, accepted 